\title{
The CHARMS Study: cardiac patients' experiences of sexual problems following cardiac rehabilitation
}

Molly Byrne, Sally Doherty, Andrew W Murphy, Hannah M McGee and Tiny Jaarsma

\section{Linköping University Post Print}

\section{Tweet}

N.B.: When citing this work, cite the original article.

Original Publication:

Molly Byrne, Sally Doherty, Andrew W Murphy, Hannah M McGee and Tiny Jaarsma, The CHARMS Study: cardiac patients' experiences of sexual problems following cardiac rehabilitation, 2013, European Journal of Cardiovascular Nursing, (12), 6, 558-566.

http://dx.doi.org/10.1177/1474515113477273

Copyright: Elsevier / SAGE Publications (UK and US): 12 month Embargo http://www.uk.sagepub.com/home.nav

Postprint available at: Linköping University Electronic Press http://urn.kb.se/resolve?urn=urn:nbn:se:liu:diva-99819 
Title: The CHARMS Study: Cardiac patients' experiences of sexual problems following cardiac rehabilitation.

Authors:

Molly Byrne

Lecturer, School of Psychology, National University of Ireland, Galway, Ireland

Sally Doherty

Lecturer, Department of Psychology, Royal College of Surgeons in Ireland, Dublin, Ireland

Andrew W Murphy

Professor, Discipline of General Practice, National University of Ireland, Galway, Ireland

Hannah M McGee

Professor, Department of Psychology, Royal College of Surgeons in Ireland, Dublin, Ireland

Tiny Jaarsma

Professor, Department of Social and Welfare Studies, University of Linköping, Sweden

Author for correspondence:

Dr Molly Byrne, School of Psychology, National University of Ireland, Galway, Ireland.

Phone: + 35391495182 Email: molly.byrne@ nuigalway.ie 
Abstract

Background: Sexual problems are common among cardiac patients. Further information is required on patients' experiences of sexuality, and preferences for, sexual counselling.

Aim: To characterise sexual dysfunction and related factors among patients following cardiac rehabilitation and examine related treatment delivery.

Methods: Telephone interviews with 382 patients (32\% response rate) recruited from six hospital rehabilitation centres.

Results: Seventy-nine percent were male; average age was 64 years (SD 9.8). Forty-seven percent of the total sample reported no sexual relations in the previous year, and nearly a half of sexually active respondents reported at least one sexual problem. Erectile dysfunction (reported by 33\%) and lack of interest in sex (reported by $10 \%$ ) were the most common problems for men and women respectively. Twenty-three percent reported that sex had deteriorated for them since their cardiac event, and for half of these, this was considered a serious problem. In logistic regression analysis, higher anxiety (HADS) and being male were associated with reporting a sexual problem $\left(\chi^{2}=37.85, \mathrm{p}<0.001\right)$. Sixty-six percent reported that sex was never discussed by a health professional and satisfaction with this aspect of care was low. Patients wanted these issues to be addressed and the majority $(63 \%)$ claimed they would find it easy to discuss sexual problems with a health professional.

Conclusions: Sexual inactivity and sexual problems are common in this group. Health professionals should address sexual issues with their patients, ideally in a private setting and within the broader context of addressing psychological wellbeing.

Keywords: cardiovascular diseases; cardiac rehabilitation; sexual problems; sexual dysfunction; erectile dysfunction; sexual assessment and counselling. 


\section{Introduction}

Recent guidelines in the area of sexual activity and cardiovascular disease ${ }^{1}$ conclude that sexual activity is an important aspect of quality of life for those with cardiovascular disease and that sexual counselling should form an important component of rehabilitation services.

Sexual problems are more prevalent among both men ${ }^{2-3}$ and women ${ }^{4}$ with cardiovascular disease than those without disease. Prevalence rates for sexual problems for men range from $20 \%^{2,5}$ to $70 \%{ }^{6-7}$, with a number of studies reporting levels around $50 \%^{8-10}$. Rates vary according to age and disease characteristics of the sample, as well as how sexual function is measured. Although women are less commonly included in research in this area, studies examining sexual problems among women with coronary heart disease suggest that sexual problems are more prevalent among this group (compared to women without disease) and report prevalence figures ranging from $43 \%^{5}$ to $87 \%^{11}$. A lack of sexual activity appears to be particularly common among adult women with cardiovascular disease ${ }^{12}$.

Reasons for the association between sexual problems and cardiovascular disease include physical vascular causes ${ }^{13}$, fear of sexual activity provoking cardiac symptoms or a cardiac event ${ }^{14}$, patient/partner relationship changes following a cardiac event ${ }^{15}$ and associations with psychological problems such as depression ${ }^{5}$. Although there is evidence to suggest that some cardiac medications, including beta blockers and lipid lowering medications, may have sexual side effects ${ }^{6}$, more recent analyses have concluded that cardiovascular medications are uncommonly the true cause of sexual problems ${ }^{1}$.

Despite the fact that most cardiovascular patients are interested in receiving information on sexual health and/or therapy to improve sexual dysfunction ${ }^{16}$, sexual health and treatment options are rarely discussed or initiated during consultations with health professionals ${ }^{17-20}$. Patients and their partners are reluctant to approach their cardiac team or general practitioner on issues related to sexual concerns ${ }^{21}$. Barriers include feeling embarrassed or believing that the doctor is not experienced enough to understand the patient's concerns ${ }^{22}$ and stereotyped attitudes relating to age and gender ${ }^{23}$.

Further research is required regarding patients' and their partners' needs and preferences for information and support in this area ${ }^{19}$. As we know sexual behaviour and attitudes are likely to be significantly influenced by culture and country ${ }^{24}$, and we currently have no information from an Irish setting. In the CHARMS (Cardiac

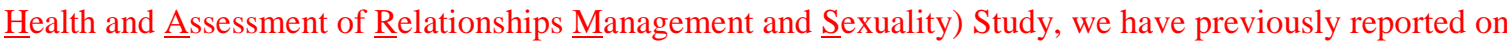


health care provider attitudes and behaviour in relation to sexual assessment and counselling ${ }^{17} 18$. In this paper we characterise sexual dysfunction as reported by patients with a cardiac diagnosis and examine related factors. A secondary aim was to describe the patients' experience of the identification of sexual dysfunction following a cardiac event and related treatment delivery from health care providers. Such a multi-faceted evaluation in one country, seeking multiple perspectives, may provide a useful model for considering similar issues elsewhere.

Specifically, in our study of patients who had recently completed phase 3 hospital cardiac rehabilitation, the research questions were:

1. What is the frequency of sexual activity and satisfaction with sexual relationships?

2. What are the extent, types and associated factors of sexual problems before and after a coronary event?

3. What are patients' experiences of how sexual health problems are treated within health services? 


\section{Methods}

\subsection{Participants}

To obtain a representative sample of patients attending cardiac rehabilitation, we calculated that we would require a sample size of 357 patients, to allow for $+/-5 \%$ margin of error, based on an estimated population size of 5000 patients (all patients attending phase 3 cardiac rehabilitation in a year) ${ }^{25}$. To achieve this sample size, we estimated that we would need to recruit around six hospital cardiac rehabilitation centres.

There are 38 hospital cardiac rehabilitation centres in the Republic of Ireland. Small centres (i.e. centres with fewer than 40 patients attending cardiac rehabilitation per year, $n=10$ ) were excluded, as these were deemed unlikely to provide adequate patient numbers for the study. Remaining centres were categorised into the eight geographically representative hospital groupings in the country, and within groupings, ranked based on size (reported patient numbers attending cardiac rehabilitation, with largest centres ranked first). Centres were selected for invitation by purposively sampling from each region to achieve a nationally representative sample, starting with the largest centres. To recruit six centres, sixteen hospital centres were invited to participate. Three centres were unable to participate due to perceived administrative limitations and seven centres were not interested. Inviting largest centres first was a pragmatic decision to enable the research team to recruit an adequate sample size of patients within the time and resources available. Five of the eight geographic regions were represented in the final sample.

Our inclusion criteria for patients were that they were over the age of 18 and had attended phase 3 cardiac rehabilitation services in the hospital centre in the previous two years but not within the previous two months of data collection. The only exclusion criterion was record of death since attending cardiac rehabilitation. Ethical approval for the study was obtained from the Research Ethics Committee of the National University of Ireland, Galway and from each participating hospital.

\subsection{Measures}

\subsubsection{Demographic and clinical data}

Demographic and clinical data were provided by responses to 12 questions including: gender, age, educational level, marital status, medical card/health insurance status, self-reported morbidities, current medications, use of 
medication for sexual function and details of participation in hospital cardiac rehabilitation (when they attended).

\subsubsection{Psychological and physical health}

Anxiety and depression were measured using the Hospital Anxiety and Depression Scale (HADS) ${ }^{26}$. Total scores for anxiety and depression range from 0 to 21 , with higher scores indicating higher levels of symptomatology. On either the anxiety or depression subscale, a score of 7 or less is considered normal, a score of $8-10$ is considered to indicate possible psychological distress and 11 or higher to indicate probable psychological distress. Physical health was measured by responses to the question: 'Which of the following best describes you physical health?' where five options were possible: excellent, very good, good, fair or poor.

\subsubsection{Sexual activity}

Questions on sexual activity and sexual problems were replicated from the Irish (general population) Study on Sexual Health and Relationships (ISSHR) ${ }^{27}$. Sexual activity related questions included: number of sexual partners (options were: $0,1,2,3$, or more than 3), frequency of sexual activity in the last year (options were 0 , less than once a month, once or twice a month, once or twice a week, twice or three times a week, more than three times a week), physical and emotional satisfaction with current sexual activity (on five point Likert scales from extremely to not at all) and desire to have sex more or less often (on five point Likert scale, from much more to much less often).

\subsubsection{Sexual problems}

Respondents were asked about their experience of sexual problems in the six month period preceding their coronary event or procedure. Typical sexual health problems as assessed by Laumann ${ }^{28}$ in a major US study and utilised in the ISSHR were included. Respondents were asked to indicate whether they had experienced each of the listed sexual problems for a period of one month or more, answering either yes or no to each problem. Listed problems included: lacked interest in sex, did not find sex pleasurable, unable to climax, climaxed too quickly (men only), trouble maintaining an erection (men only), physical pain during intercourse, trouble becoming lubricated (women only), feeling anxious about ability to perform and other (asked to specify). Respondents were asked if they had sought professional help for identified sexual problems. 
Respondents were then asked to indicate whether they had experienced the same sexual problems for a period of one month or more, since their coronary event or procedure, and whether they had sought help for the problem. Respondents were asked to rate how difficult/easy they would find talking to a health professional about a sexual health problem, if they had one, on a five point Likert scale, from very difficult to very easy.

Respondents rated agreement with a list of 14 potential barriers to discussing sexual problems with health professionals (derived from a number of previous studies) ${ }^{17,29}$, on a six point Likert scale from strongly disagree to strongly agree. Barriers included items like 'my health professional doesn't have enough time to discuss my sexual health problems', 'my health professional lacks knowledge in this area' and 'I would feel embarrassment about discussing sex'.

Respondents were asked if sex had changed for them since they were diagnosed with heart disease (response options: yes, for the better; yes, for the worse; no). They were asked to rate how serious a problem for them it was if they reported a deterioration in sex following diagnosis, on a four point Likert scale from 'a very serious problem' to 'not really a problem at all'.

\subsubsection{Sexual treatment experiences}

Respondents were asked if any health professional had discussed sex with them in the context of their cardiac condition (yes or no). If sex had been discussed, they were asked to indicate with whom (doctor, nurse, psychologist or other) and in which setting (cardiac rehabilitation, general practice or other). They were asked to rate their satisfaction with the way sex had been addressed within cardiac related health care consultations (on a five point Likert scale from extremely satisfied to not at all satisfied), and if they would have liked an opportunity to discuss sex (further) in relation to their heart disease (response options: yes, no or not sure).

\subsection{Procedure}

All patients meeting inclusion criteria within participating centres were mailed a letter of invite to participate. If they did not opt out by return of a prepaid card to the researcher, the researcher contacted them by phone within 2-4 weeks of sending the invite letter. The interviewer addressed any questions and verbal consent to participate was sought over the phone before commencing each interview. All telephone interviews were conducted by one of the authors (SD) between June 2010 and August 2011. Interview responses were recorded on paper 
questionnaires, which were stored confidentially. Interviews lasted on average 30 minutes [range 20 - 90 minutes]. If patients failed to answer the phone after the third phone call attempt, they were not contacted again.

\subsection{Statistical analysis}

Questionnaire data were input to and analysed using PASW 18 Statistical package. Comparisons between groups were conducted using t-tests for continuous variables and Chi square tests for categorical variables. A logistic regression binary analysis was conducted to assess the strength of predictor variables for sexual function problems. A p value of $<0.05$ was considered statistically significant. 


\section{Results}

Three hundred and eighty two patients completed structured telephone interviews, out of 1180 contactable patients, giving a response rate of $32.4 \%$. Response rates did not differ between men and women $\left(\chi^{2}=4.08, p=\right.$ $0.25)$.

\subsection{Sample characteristics}

Demographic and clinical characteristics are presented in Table 1. The majority (79\%) were men; the average age 64 years. Most were married or living with a partner. The most commonly reported cardiac event was myocardial infarction (56\%). Seventy percent reported percutaneous coronary intervention (PCI) and 20 percent reported a coronary artery bypass graft. Anxiety (HADS-A $\geq 8$ ) was more prevalent than depression (HADS-D $\geq 8)$. The majority of the sample reported that their physical health was very good $(33 \%, n=127)$ or good (34\%, $\mathrm{n}=129$ ). In comparison to national population estimates for patients attending hospital cardiac rehabilitation, our sample were slightly more likely to be male (population estimates are $67 \%$ male), but are comparable in terms of age (population estimates for average age are 62 years) ${ }^{30}$.

+++ Insert Table 1 here +++

\subsection{Sexual activity}

Forty seven percent $(n=181)$ reported no sexual intercourse at all in the previous year. Fourteen percent $(n=55)$ said they had sex at least once a week, 19\% $(n=72)$ said they had sex less often than once a week but at least once a month, and $19 \%(n=71)$ said they had sex less frequently than once a month but more frequently than once a year. When participants were asked about their satisfaction with frequency, 53\% $(n=107)$ reported they would like to have sex a bit or much more often.

\subsection{Sexual problems}

The frequency of sexual problems for the whole sample, both before and after either their coronary event or diagnosis, is shown in Table 2. When we examine only those who are sexually active (i.e. those who have had at least one sexual partner in the last year; $n=211$ ), the percentage of those who reported a sexual problem rises to $46 \%(n=96)$. For men the prevalence rate was $47 \%(n=86)$ and for women $37 \%(n=10)$. 
For men, erectile dysfunction is the most commonly reported type of problem. Nearly a third of all men reported having a problem with maintaining an erection both before their coronary event and since their coronary event (32\% and 33\% respectively). For women, the most common problem reported was lacking interest in sex (16\% before event and $10 \%$ since event).

When asked about the use of medication to increase sexual function, 24\% $(n=72)$ of men reported use ever, and $6 \%(n=19)$ reported regular use. No woman reported use of medications to increase sexual function.

When participants were asked if sex had changed for them since their diagnosis/event, 23\% (n=89) said it had changed for the worse; of these, $53 \%(n=47)$ indicated that this was either a very or somewhat serious problem for them.

+++ Insert Table 2 here +++

3.4 Which factors were associated with sexual function problems?

In univariate analysis, of all the demographic, clinical and psychological variables examined, we identified gender (men $41 \%$ versus women $12 \%$ reported sexual problems; $\chi^{2}=23.33, \mathrm{p}<0.001$ ); diagnosis of diabetes mellitus (those with diabetes $46 \%$ versus those without diabetes $32 \%$ reported sexual problems; $\chi^{2}=5.28$, $\mathrm{p}=0.02$ ) and HADS anxiety (mean HADS anxiety score for those with sexual problems was 6.2 (4.0) and mean for those without sexual problems was $5.2(4.0)(\mathrm{t}=-2.22, \mathrm{p}=0.027))$ as significantly related to having sexual problems.

When these predictor variables were entered into a logistic binary regression analysis, the model significantly predicted sexual problems $\left(\chi^{2}=37.85, \mathrm{p}<0.001\right)$. The model as a whole correctly predicted $66.3 \%$ of cases to either experiencing sexual problems or not. When the three predictors were entered together into the model, HADS anxiety (higher levels) and gender (being male) remained as reliable and independent predictors of sexual function problems, whereas diagnosis of diabetes dropped out. See Table 3.

+++ Insert Table 3 here +++

Of all the demographic, clinical and psychological variables which were compared between sexually active men with erectile dysfunction and without erectile dysfunction, we found that groups differed only in reported levels of anxiety and depression. We found that those who reported erectile dysfunction $(n=99)$ were more likely to 
have higher mean HADS anxiety score (6.31, SD 4.09) than those who had not experienced erectile dysfunction $(\mathrm{n}=146,4.81, \mathrm{SD} 3.40)(\mathrm{t}=3.13, \mathrm{p}<0.05)$. Those who reported erectile dysfunction were more likely to have higher mean HADS depression score (4.18, SD 3.53) than those who had not experienced erectile dysfunction $(3.01, \mathrm{SD} 2.89)(\mathrm{t}=2.73, \mathrm{p}<0.05)$.

3.5 Sexual counselling in health services

When asked if any health professional has raised the issue of sex since their cardiac condition was diagnosed, $66 \%(\mathrm{n}=249)$ said it had never been discussed. Eighty six percent of those who reported that the topic had been raised by a health professional (56\% psychologist, $30 \%$ nurse and $7 \%$ a doctor) said that this took place in hospital cardiac rehabilitation. When asked to rate their satisfaction with how these issues had been addressed within the health services, $24 \%(n=57)$ claimed they were extremely or very satisfied, $61 \%(n=142)$ claimed they were moderately or slightly satisfied, whereas $15 \%(n=34)$ claimed they were not at all satisfied. When asked if they would have liked the opportunity to discuss sex (or discuss sex further) with a health professional, $48 \%(n=183)$ would have liked this opportunity, whereas $37 \%(n=140)$ would not have liked this opportunity.

When asked if all types of sexual health services were available to them, the majority of respondents $(n=296$, $78 \%$ ), said that their preference would be to consult with a general practitioner. Thirty two percent ( $\mathrm{n}=121)$ said they would find it either difficult or very difficult to talk to a health professional about a sexual problem, whereas $63 \%(n=238)$ said they would find it easy or very easy. Women were more likely than men to find it difficult or very difficult to talk to a health professional about a sexual health problem (50\% for women versus $27 \%$ for men).

The most commonly endorsed barriers to discussing sexual problems with a health professional were the presence of a third party (not being alone with health professional) (47\% agreed), not feeling ready to discuss sexual problems (35\% agreed) and feelings of embarrassment (34\% agreed). 


\section{Discussion}

This study is novel in reporting nationally representative data from both male and female cardiac patients, and addressing their experience of sexual activity after their cardiac event as well as their views on how sexual problems are addressed within health services. One of the most significant findings in our study was the high levels of sexual inactivity in the previous year (around half of the sample), significantly higher than general population estimates for this age group of around $21 \%$ of men and $33 \%$ of women ${ }^{27}$. It is possible that this high level of sexual inactivity may be at least to some degree as a result of unresolved sexual problems.

Sexual problems

The rate of self-reported sexual problems in our study ( $46 \%$ of those who are sexually active) is similar to previous studies with cardiovascular samples ${ }^{2}$. Men were significantly more likely than women to report sexual problems. Among sexually active women, the prevalence figure for sexual problems was $37 \%$, lower than prevalence levels found in previous studies ${ }^{5,31-32}$. The most commonly reported sexual problem was lack of interest in sex. Our study is similar to previous studies of this population in reporting high levels of women ( $66 \%$ in our study) who were not sexually active ${ }^{12,31}$. There are conflicting findings in the literature when comparing men and women in relation to the impact of heart disease on their sexual activity, with some reporting women as less likely to return to sexual activity after a cardiac event ${ }^{33}$, but others finding no difference between men and women ${ }^{34}$. Our data suggest that women $d o$ seem to be less likely to engage in sexual activity after a coronary event than men, but this finding must be treated with caution as our sample size for women is small, and the finding is likely in part due to the fact that women with heart disease are generally older than men, and their partners are therefore more likely to be already deceased.

For men, the most frequently reported problem was erectile dysfunction, with around one third reporting this problem, falling somewhere in between rates reported previously ${ }^{2,5,7,9-10,35}$. Previous studies which report lower levels had samples with a younger mean age and/or involve healthier participants than our sample while studies which report higher levels have samples with a higher mean age than our sample, or involve patients at more critical time points in their illness trajectory, e.g. currently undergoing coronary angiography ${ }^{6}$. All previous studies reporting higher levels of erectile dysfunction employ the International Index of Erectile Function (IIEF) component of the Sexual Health Inventory for Men (SHIM) ${ }^{36}$. It has been suggested that the IIEF is likely to overestimate actual levels of erectile dysfunction ${ }^{5}$. 
Our figure for erectile dysfunction is significantly higher than general population prevalence rates ${ }^{27}$ where $26 \%$ of men aged 55-64 reported having experienced one month or more of erectile dysfunction in the last 5 years. The time frames (one year versus five years) are not directly comparable, so within the five year time frame, our sample would be likely to report even higher levels of erectile dysfunction.

There was no change in frequency of reporting a sexual problem before or after diagnosis or coronary event. For men reporting erectile dysfunction, this fits with the finding that erectile dysfunction commonly precedes diagnosis with cardiovascular disease ${ }^{13}$. However, nearly a quarter of the sample said that sex had deteriorated for them since their event, and over half of these indicated that it was a serious problem for them.

Factors associated with sexual problems

We found that gender (being male), having been diagnosed with diabetes mellitus and higher anxiety levels were associated with the presence of sexual problems. Diabetes mellitus has been identified previously as a risk factor for sexual dysfunction and anxiety has been identified previously as a risk factor for erectile dysfunction ${ }^{8}$.

When we examined erectile dysfunction specifically, we found that raised levels of anxiety and depression, but not self reported physical health, were significant associated with erectile dysfunction among sexually active men. These findings confirm previous reports $5,35,37$.

Seeking professional help for sexual problems

In line with previous research ${ }^{19,38}$, a significant majority of patients reported that sex had never been discussed with them by a health professional, and when these discussions had taken place, satisfaction was relatively low. Interest in discussing aspects of sexual life was variable, but nearly half the sample said they would have liked some or more discussion of sexual issues within health services. However, similar to previous studies ${ }^{21}$, patients in our study were reluctant themselves to raise the issue of sexual problems with a health professional. The most common professional with whom sexual problems were discussed in cardiac rehabilitation was a psychologist however, it is important to note that only a minority of cardiac rehabilitation services in Ireland actually employ a psychologist. One of the primary barriers to discussing sexual problems was lack of private setting; for the majority cardiac rehabilitation is experienced as part of a group, with limited opportunities to address issues privately with a health professional.

Limitations 
Our sample were heterogeneous regarding their underlying diagnosis and reason for attending cardiac rehabilitation and we do not have detailed information on clinical history.

While our sample is likely to be representative of patients in general who have completed phase 3 hospital cardiac rehabilitation, we are limited in our ability to conduct sub-group analysis. In addition, as we selected larger hospital centres only in this study, our findings may not be representative of smaller hospital centres. However, the included centres were no more likely than non-included centres to employ a psychologist; this may indicate that large and small centres do not differ systematically in the service they provide. As only patients were consulted, the views of partners are absent.

Our low response rate may bias our findings, due to the effects of self-selection. It has been suggested that surveys of sexual attitudes and behaviour may overestimate sexual liberalism, activity and adversity ${ }^{39}$.

The retrospective nature of data relating to sexual function problems in the last year and particularly before their coronary diagnosis or coronary event means that responses may be subject to memory bias.

The data we gathered on medications were unreliable, as participants were often unsure about which medication they had been prescribed, and therefore we have not reported this data. More information on patients' medications would have been useful, as such medications may have influenced sexual dysfunction among our sample.

To our knowledge, ours is the first study in this area to administer questionnaires to patients via telephone interview. This method was selected in an attempt to maximise the quality of our data, by allowing the researcher to further clarify the meanings of questions, minimise misunderstandings and reduce missing data, while also allowing respondents to benefit from the anonymity associated with a telephone interview, rather than a face-to-face interview. We believe that we achieved these aims and had virtually no missing data. However, it is also possible that administration by the researcher in this way might have influenced the responses of participants.

\section{Conclusion}

Levels of sexual inactivity and sexual problems were higher in our sample than the general population. A sizeable minority reported perceiving the deterioration in their sexual lives following diagnosis/coronary event as a serious problem. However, few have raised these issues with a health professional and satisfaction with how 
these issues are currently dealt with in health services is low. Raised anxiety levels were associated with sexual dysfunction, and both higher anxiety levels and higher levels of depression were observed in those reporting erectile dysfunction compared to those without such problems.

Among our sample, there was a desire for health professionals to address these issues within services, and a substantial proportion claimed that they would find it easy to discuss sexual problems with a health professional. Health professionals working in cardiac rehabilitation and primary care should address sexual issues with their patients, ideally with the option of doing so in a private setting and within the broader context of psychological wellbeing. Psychologists working within cardiac rehabilitation may be ideally placed to address these issues; however as only nine of the thirty-eight centres in Ireland currently employ a psychologist, other professional groups are also required to address these issues with patients. Addressing these issues early in cardiac rehabilitation, reassuring patients when it is safe to return to sexual activity, may prevent sexual problems arising and reduce levels of sexual inactivity among this population.

\section{Acknowledgements:}

Funding source: The work was supported by the Health Research Board (Ireland). Grant number: RP/2007/124 Patients and participating hospitals: University Hospital Galway; Beaumont Hospital Dublin; Adelaide Meath incorporating the National Children's Hospital (AMNCH) Tallaght; St. Colmcille's Hospital, Loughlinstown, Co Dublin; St. James’s Hospital, Dublin; Our Lady’s Hospital, Navan.

The CHARMS Study Steering Committee also included: Ms Kate O Donovan, Mater Hospital, Dublin, Ireland. Declaration of Conflicting Interests: None declared 
1. Levine GN, Steinke EE, Bakaeen FG, et al. Sexual Activity and Cardiovascular Disease. Circulation. 2012; 125: 1058-72.

2. Schumann J, Zellweger MJ, Di Valentino M, Piazzalonga S and Hoffmann A. Sexual Dysfunction before and after Cardiac Rehabilitation. Rehabilitation Research and Practice. 2010; Article ID 823060: 10.1155/2010/823060.

3. Schwarz ER. Sexual dysfunction and its relation to heart disease (Editorial). International Journal of Impotence Research. 2005; 17: S1-S3.

4. Kütmeça C and Yurtseverb S. Effects of sexual function of essential hypertensions in women. European Journal of Cardiovascular Nursing. 2011; 10: 56-63.

5. Kriston L, Gunzler C, Agyemang A, Bengel J, Berner MM and Group SS. Effect of sexual function on health-related quality of life mediated by depressive symptoms in cardiac rehabilitation. findings of the SPARK project in 493 patients. Journal of Sexual Medicine. 2010; 7: 2044-55.

6. Kloner RA, Mullin SH, Shook T, et al. Erectile Dysfunction in the Cardiac Patient: How Common and Should We Treat? Part 2 of 2. Journal of Urology. 2003; 170: S46-S50.

7. Mulat B, Arbel Y, Mashav N, et al. Depressive Symptoms and Erectile Dysfunction in Men With Coronary Artery Disease. Urology. 2010; 75: 104-7.

8. Maroto-Montero MJ, Portuondo-Maseda MT, Lozano-Suárez M, et al. Erectile Dysfunction in Patients in a Cardiac Rehabilitation Program. Revista Espanola de Cardiologia. 2008; 61: 917-22.

9. Böhm M, Baumhäkel M, Probstfield JL, et al. Sexual function, satisfaction, and association of erectile dysfunction with cardiovascular disease and risk factors in cardiovascular high-risk patients: Substudy of the ONgoing Telmisartan Alone and in Combination with Ramipril Global Endpoint Trial/Telmisartan Randomized AssessmeNT 
Study in ACE-INtolerant Subjects with Cardiovascular Disease (ONTARGET/TRANSCEND). American Heart Journal. 2007; 154: 94-101.

10. Foroutan SK and Rajabi M. Erectile dysfunction in men with angiographically documented coronary artery disease. Urology journal. 2007; 4: 28-32.

11. Schwarz E, Kapur V, Bionat S, Rastogi S, Gupta R and Rosanio S. The Prevalence and Clinical Relevance of Sexual Dysfunction in Women and Men with Chronic Heart Failure International Journal of Impotence Research. 2008; 21: 85-91.

12. Megiddo E, Justo D, Arbel Y, Oren A, Heruti R and Banai S. Sexual dysfunction and coronary artery disease in adult women. Harefuah. 2009; 148: 611-4.

13. Dong J-Y, Zhang Y-H and Qin L-Q. Erectile Dysfunction and Risk of Cardiovascular Disease: Meta-Analysis of Prospective Cohort Studies. Journal of the American College of Cardiology. 2011; 58: 1378-85.

14. Katz A. Sexuality and myocardial infarction. AmericanJournal of Nursing. 2007; 107: 49-52.

15. Dalteg T, Benzein E, Fridlund B and Malm D. Cardiac disease and its consequences on the partner relationship: A systematic review. European Journal of Cardiovascular Nursing. 2011; 10: 140-9.

16. Akdolun N and Terakye G. Sexual problems before and after myocardial infarction: patients' needs for information. Rehabilitation Nursing. 2001; 26: 152-8.

17. Byrne M, Doherty S, McGee HM and Murphy AW. General practitioners views about discussing sexual issues with patients with coronary heart disease: a national survey in Ireland. BMC Family Practice. 2010; 11: 40.

18. Doherty S, Byrne M, Murphy AW and McGee HM. Cardiac rehabilitation staff views about discussing sexual issues with coronary heart disease patients: A national survey in Ireland. European Journal of Cardiovascular Nursing. 2011; 10: 101-7. 
19. Ivarsson B, Fridlund B and Sjoberg T. Information from health care professionals about sexual function and coexistence after myocardial infarction: a Swedish national survey. Heart \& Lung. 2009; 38: 330-5.

20. Jaarsma T, Stromberg A, B F, et al. Sexual counselling of cardiac patients:nurses' perception of practice, responsibility and confidence. European Journal of Cardiovascular Nursing. 2010; 9: 24-9.

21. Ben-Zion I and Shiber A. Heart to heart: rehabilitation of sexuality in cardiac patients. Harefuah. 2006; 145: 350-1.

22. Gott M and Hinchliff S. Barriers to seeking treatment for sexual problems in primary care: a qualitative study with older people. Family Practice. 2003; 20: 690-5.

23. Albarran JW and Bridger S. Problems with providing education on resuming sexual activity after myocardial infarction: developing written information for patients. Intensive and Critical Care Nursing. 1997; 13: 2-11.

24. Goossens E, Norekval TM, Faerch J, et al. Sexual counselling of cardiac patients in Europe: culture matters. International Journal of Clinical Practice. 2011; 65: 1092-9.

25. Agresti A and Coull BA. Approximate is better than "exact" for interval estimation of binomial proportions. Amer Stat 1998; 52: 119-26.

26. Zigmond AS and Snaith RP. The hospital anxiety and depression scale. Acta Psychiatrica Scandinavica. 1983; 67: 361-70.

27. Layte R, McGee HM, Quail A, Rundle K, Cousins G and Donnelly C. The Irish Study of Sexual Health \& Relationships. Dublin2006.

28. Laumann E, Gagnon JH, Michael TM and Micheals S. The Social Organisation of Sexuality: Sexual Practices in the United States. Chicago: University of Chicago Press, 1994. 
29. Thompson K, Casson K, Fleming P, Dobbs F, Parahoo K and Armstrong J. Sexual health promotion in primary care - activities and views of general practitioners and practice nurses. Primary Health Care Research and Development. 2008; 9: 319-30.

30. Delaney M, Flynn R, Kiernan M, et al. Third National Survey of Cardiac Rehabilitaion Service Provision in Ireland: progress on the 1999 National Cardiovascular Health Strategy Recommendations. Royal College of Surgeons in Ireland, 2006, p. http://epubs.rcsi.ie/psycholrep/2.

31. Addis IB, Ireland CC, Vittinghoff E, Lin F, Stuenkel CA and Hulley S. Sexual Activity and Function in Postmenopausal Women With Heart Disease. Obstetrics \& Gynecology. 2005; 106: 121-7 10.1097/01.AOG.0000165276.85777.fb.

32. Kaya C, Yilmaz G, Nurkalem Z, Ilktac A and Karaman MI. Sexual function in women with coronary artery disease: a preliminary study. International Journal of Impotence Research. Nature Publishing Group, 2007, p. 326-9.

33. Stern MJ, Pascale L and Ackerman A. Life Adjustment Postmyocardial Infarction: Determining Predictive Variables. Archives of Internal Medicine. 1977; 137: 1680-5.

34. Drory Y, Kravetz S and Weingarten M. Comparison of sexual activity of women and men after a first acute myocardial infarction. The American Journal of Cardiology. 2000; 85: 1283-7.

35. Traeen B and Olsen S. Sexual dysfunction and sexual well-being in people with heart disease. Sexual \& Relationship Therapy. 2007; 22: 193-208.

36. Day D, Ambegaonkar A, Harriot K and McDaniel A. A new tool for predicting erectile dysfunction. Advances in Therapy. 2001; 18: 131-9.

37. Rosen RC, Fisher WA, Eardley I, Niederberger C, Nadel A and Sand M. The multinational Men's Attitudes to Life Events and Sexuality (MALES) study: I. Prevalence of 
erectile dysfunction and related health concerns in the general population. Current Medical Research and Opinion. 2004; 20: 607-17.

38. Solomon H, DeBusk RF and Jackson G. Erectile dysfunction: The need to be evaluated, the right to be treated. American Heart Journal. 2005; 150: 620-6.

39. Dunne MP, Martin NG, Bailey JM, et al. Participation bias in a sexuality survey: psychological and behavioural characteristics of responders and non-responders. International Journal of Epidemiology. 1997; 26: 844-54. 
Table 1: Sample demographic and clinical characteristics (n (\%) for categorical variables)

\begin{tabular}{|c|c|c|c|}
\hline Characteristic & $\operatorname{Men}(n=301,79 \%)$ & Women $(\mathrm{n}=81,21 \%)$ & Total $(\mathrm{N}=382)$ \\
\hline Age (mean, SD) & $64(9.8)$ & $65(9.8)$ & $64(9.8)$ \\
\hline \multicolumn{4}{|l|}{ Education } \\
\hline $\begin{array}{l}\text { No schooling/ completed } \\
\text { primary education only }\end{array}$ & $82(27)$ & $29(36)$ & $111(29)$ \\
\hline $\begin{array}{l}\text { - Some or completed secondary } \\
\text { education only }\end{array}$ & $127(42)$ & $37(46)$ & $164(43)$ \\
\hline $\begin{array}{l}\text { - Some or completed third level } \\
\text { education }\end{array}$ & $92(31)$ & $15(18)$ & $107(28)$ \\
\hline \multicolumn{4}{|l|}{ Marital status } \\
\hline - Married/living with partner & $237(79)$ & $49(60)$ & $286(75)$ \\
\hline - Widowed & $24(8)$ & $20(25)$ & $44(12)$ \\
\hline - $\quad$ Separated/divorced & $20(7)$ & $4(5)$ & $23(6)$ \\
\hline - $\quad$ Never married & $20(6)$ & $8(10)$ & $28(7)$ \\
\hline \multicolumn{4}{|l|}{$\begin{array}{l}\text { Ever diagnosed with medical } \\
\text { condition }\end{array}$} \\
\hline - Angina & $119(40)$ & $30(37)$ & $149(39)$ \\
\hline - Myocardial infarction & $169(56)$ & $44(54)$ & $213(56)$ \\
\hline - High blood pressure & $155(52)$ & $46(57)$ & $201(53)$ \\
\hline - $\quad$ Stroke & $22(7)$ & $8(10)$ & $30(8)$ \\
\hline - Diabetes & $72(24)$ & $6(7)$ & $78(20)$ \\
\hline - High cholesterol & $185(62)$ & $50(62)$ & $235(62)$ \\
\hline - Depression & $48(16)$ & $20(25)$ & $68(18)$ \\
\hline - $\quad$ Anxiety & $42(14)$ & $19(24)$ & $61(16)$ \\
\hline \multicolumn{4}{|l|}{ Cardiac procedures } \\
\hline - Coronary Artery Bypass Graft & $66(22)$ & $12(15)$ & $78(20)$ \\
\hline $\begin{array}{l}\text { Percutaneous coronary } \\
\text { interventions (PCI: stent, } \\
\text { angioplasty) }\end{array}$ & $215(71)$ & $53(65)$ & $268(70)$ \\
\hline \multicolumn{4}{|l|}{ HADS anxiety } \\
\hline - $\quad$ Normal $(<8)$ & $216(72)$ & $47(59)$ & $263(69)$ \\
\hline - $\quad$ Borderline (8-10) & $53(18)$ & $19(24)$ & 72 (19) \\
\hline - Abnormal/clinical $>11$ & $30(10)$ & $15(19)$ & $45(12)$ \\
\hline \multicolumn{4}{|l|}{ HADS depression } \\
\hline - $\quad$ Normal $(<8)$ & $264(88)$ & $73(91)$ & $337(89)$ \\
\hline - $\quad$ Borderline $(8-10)$ & $17(6)$ & $3(4)$ & $20(5)$ \\
\hline - Abnormal/clinical >11 & $20(7)$ & $4(5)$ & $24(6)$ \\
\hline
\end{tabular}


Table 2: Prevalence of sexual problems before and after diagnosis/coronary event for men and women $(\mathrm{N}=382)$

\begin{tabular}{|l|l|l|l|l|}
\hline Problem & $\begin{array}{l}\text { Problem before } \\
\text { event (had one } \\
\text { month or more } \\
\text { when...) } \\
\mathrm{n}\end{array}$ & $\begin{array}{l}\text { Problem } \\
\text { before event }\end{array}$ & $\begin{array}{l}\text { Problem after event } \\
\text { (had one month or } \\
\text { more when...) }\end{array}$ & $\begin{array}{l}\text { Problem after } \\
\text { event }\end{array}$ \\
\hline Men (n=301) & & & $\mathrm{n}$ & $\%$ \\
\hline Lacked interest in having sex & 41 & 14 & 44 & 15 \\
\hline Did not find sex pleasurable & 41 & 14 & 36 & 12 \\
\hline Unable to come to orgasm & 53 & 18 & 56 & 19 \\
\hline Came to orgasm too quickly & 58 & 19 & 55 & 18 \\
\hline Trouble maintaining an erection & 97 & 32 & 99 & 33 \\
\hline $\begin{array}{l}\text { Felt anxious about ability to } \\
\text { perform sexually }\end{array}$ & 15 & 5 & 13 & 4 \\
\hline Women (n=81) & & & & 10 \\
\hline Lacked interest in having sex & 13 & 16 & 8 & 6 \\
\hline Did not find sex pleasurable & 11 & 14 & 5 & 4 \\
\hline Unable to come to orgasm & 5 & 6 & 3 & 2 \\
\hline Pain during intercourse & 3 & 4 & 2 & 6 \\
\hline Vaginal dryness & 6 & 6 & 5 & 0 \\
\hline $\begin{array}{l}\text { Felt anxious about ability to } \\
\text { perform sexually }\end{array}$ & 5 & & & \\
\hline
\end{tabular}


Table 3: Multivariate logistic regression analysis of predictors of reporting any sexual problem for a period of at least a month within the previous 12 months $(n=380)$

\begin{tabular}{|l|l|l|l|}
\hline Predictor & Odds ratio & $95 \%$ confidence interval & P value \\
\hline $\begin{array}{l}\text { Diagnosis of diabetes } \\
\text { mellitus }\end{array}$ & 1.467 & $0.866-2.483$ & 0.154 \\
\hline $\begin{array}{l}\text { Total HADS anxiety (per 1 } \\
\text { point increase on scale) }\end{array}$ & 1.093 & $1.033-1.158$ & 0.002 \\
\hline Gender (male) & 5.592 & $2.688-11.631$ & $<0.001$ \\
\hline
\end{tabular}

